Retrospective Evaluation

\title{
Interventional Techniques in Managing Persistent Pain After Vertebral Augmentation Procedures: A Retrospective Evaluation
}

\author{
Bassem A. Georgy, MD
}

From: Interventional Neuroradiology and Pain Management, Valley Radiology Consultants University of California, San Diego

Dr. Georgy is a Neurointerventional Radiologist with Valley Radiology

Consultants and University of California, San Diego, CA.

Address correspondence: Bassem Georgy, MD, MSc 5458 Coach Lane

San Diego, CA 92130 bgeorgy@earthlink.net

Disclaimer: There was no external funding in preparation of this manuscript. Conflict of interest: None.

Manuscript received: 07/06/2007 Accepted for publication: $08 / 15 / 2007$

Free full manuscript: www.painphysicianjournal.com
Background: Based on systematic reviews, it appears that at least $10 \%$ of patients may continue to suffer with residual or persistent pain after successful vertebral or sacral augmentation procedures.

Objective: To report and evaluate the incidence and prevalence of different spinal injections in patients who received vertebroplasty, kyphoplasty, and sacroplasty procedures for both benign and malignant compression fractures.

Design: A retrospective case review.

Methods: Retrospective review of all cases of vertebroplasty, sacroplasty, and kyphoplasty performed in a 12-month period in a single outpatient setting of interventional radiology was conducted.

Results: In a 12-month period starting from October 2005 to September 2006, 144 patients underwent cement augmentation procedures. Of the 144, 34 patients required a spinal injection procedure for residual or persistent pain within a 1-year period after the augmentation procedure.

Twenty-four patients required epidural steroid injections, 6 patients required intercostal nerve blocks, 5 patients required trigger point injections, 5 patients required sacroiliac joint injections, and 1 patient required facet joint injections. Nine patients who required lumbar epidural steroid injections and all patients who required intercostal nerve blocks and had underwent a thoracic cement augmentation procedure.

Conclusion: A small proportion of patients undergoing percutaneous cement augmentation for vertebral compression fractures or sacral insufficiency fractures potentially require spinal injections to treat residual pain after the procedure.

Key words: Kyphoplasty, vertebroplasty, sacroplasty, residual pain, vertebral compression fractures, epidural steroid injections, facet joint pain, sacroiliac joint injections, facet joint injections.

Pain Physician 2007; 10:673-676

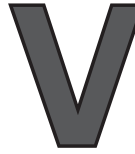

ertebral compression fractures and sacral insufficiency fractures constitute a major healthcare problem in the United States, not only because of a high incidence of these lesions but also due to their direct and indirect negative consequences for patient health-related quality of life and the costs to the healthcare system (1-7). Vertebral fractures may result in pain at, above, or below the fracture site due to loss of height caused by vertebral collapse, spinal instability, cement leakage, facet 
arthropathy, nerve root entrapment, and in many cases, surgical kyphotic deformity. Vertebroplasty and balloon kyphoplasty are 2 minimally invasive surgery approaches developed for the management of symptoms of vertebral compression fractures (13). More recently sacroplasty also has been used for treatment of sacral insufficiency fractures.

In vertebroplasty, polymethylmethacrylate (PMMA) is injected directly into a vertebral body under direct radiologic guidance. When performing kyphoplasty, a balloon tamp is usually placed inside the compressed vertebral body aiming for height restoration and formation of a cavity by compressing the cancellus bone before the PMMA injection. In sacroplasty, PMMA is injected into the sacral ala under fluoroscopic or CT guidance to stabilize stress fractures.

A number of reviews of the literature and commentaries have been performed evaluating vertebroplasty and kyphoplasty in patients with symptomatic vertebral compression fractures from osteoporotic or neoplastic etiology (1-3). Recent systematic reviews $(2,3)$ and evidence-based guidelines (1) concluded that there is level 3 or moderate evidence in management of patients with symptomatic osteoporotic vertebral compression fractures refractory to conventional medical therapy. The systematic reviews have noted that a large proportion of patients had some pain relief. However, one study (3) reported improvement was $49 \%$ to $90 \%$ of subjects with ambulation. Thus, potentially a small but significant proportion of patients may continue to be in pain after vertebroplasty, kyphoplasty, and sacroplasty. In patients with spinal pain, multiple structures may be responsible for the causation of pain, specifically in the elderly with vertebral fractures. Other structures responsible for pain include intervertebral discs, facet joints, ligaments, fascia, muscles, and nerve roots. Facet joint pain, discogenic pain, and sacroiliac joint pain have been proven to be common causes of pain with proven diagnostic techniques (1).

Burton et al (8) presented a review of the literature regarding outcomes after both vertebroplasty and kyphoplasty. They reported that certain patients, even after reasonable pain relief from the fracture site, require interventional procedures to treat either residual pain or a new type of pain that manifests after the augmentation procedure. Kim et al (9) prospectively studied 500 patients with vertebroplasty performed in both benign and malignant lesions. To confirm the most painful level among the multiple fracture sites and to get the clinical success to relieve pain they utilized facet joint blocks as prognostic indicators and performed physical examinations after the facet joint blocks at the level of the fracture as well as the adjacent levels. This retrospective evaluation was sought to evaluate the residual persistent pain after successful vertebroplasty, kyphoplasty, and sacroplasty procedures and the necessity for interventional procedures.

\section{Methods}

No institutional review board approval was required since all the data was collected retrospectively from outpatient charts. Appropriate care was taken to preserve patient privacy and identity.

Data was collected for the region of the procedure performed (thoracic, lumbar, or sacral), type of procedure performed (vertebroplasty, kyphoplasty, or sacroplasty), and spinal interventional procedure(s) required to treat residual pain. During the followup visit, within 1 month of treatment, patients were evaluated in various parameters including pain relief, complications, patient satisfaction, and finally, residual persistent pain. Those patients with significant residual persistent pain were treated with interventional techniques.

For this evaluation, 144 patients undergoing procedures at 200 levels with single or multi-level vertebroplasty, kyphoplasty, or sacroplasty for benign or malignant compression fractures or sacral insufficiency fractures were evaluated. The procedures were performed from October 2005 to September 2006.

\section{Results}

The data was available for all of the 144 patients who underwent cement augmentation procedures from October 2005 to September 2006; and 34 patients $(23.61 \%)$ complained of residual pain. This patient group consisted of 13 men and 20 women with an average age of 81.5 years.

Table 1 provides patient demographic characteristics and the interventional procedures performed. Based on the symptomatology, 26 patients were treated with epidural steroids. Of the 26 patients receiving epidural steroid injections, 8 patients underwent thoracic and lumbar vertebroplasty or kyphoplasty, 6 patients underwent lumbar vertebroplasty or kyphoplasty, 9 patients underwent thoracic vertebroplasty or kyphoplasty, and 3 patients underwent sacroplasty. All 6 patients requiring intercostal nerve blocks un- 
derwent thoracic vertebroplasty or kyphoplasty and developed radicular pain at the level of the vertebral augmentation. Five patients were treated with trigger point injections for a paraspinal focal pain with tenderness after thoracic or lumbar procedures. Five patients had sacroiliac joint injections that showed symptomatology indicating sacroiliac joint pain. Two of the 5 patients receiving sacroiliac joint injections had lumbar vertebroplasty or kyphoplasty, one had a thoracic vertebroplasty, one had sacroplasty, and final$l y$, one patient underwent thoracic and lumbar vertebroplasty. Only one patient requiring a facet joint injection underwent sacroplasty and multilevel lumbar vertebroplasty and kyphoplasty in the same setting.

Of the 34 patients undergoing interventional techniques, 6 underwent multiple procedures.

\section{Discussion}

This retrospective evaluation of 144 patients undergoing cement augmentation procedures showed 34 patients or $23.61 \%$ with residual pain. The patient group consisted of 13 men and 20 women with an average age of 81.5 years. Of these, based on the reported symptomatology and physical examination findings, 26 patients were treated with epidural steroid injections, 6 patients were treated with intercostal nerve blocks, 5 patients were treated with trigger point injections, 5 patients were treated with sacroiliac joint injections, and only 1 patient underwent facet joint injection. Six patients were treated with multiple procedures. There was no significant difference between the patients undergoing vertebroplasty or kyphoplasty or procedures performed in the thoracic, lumbar, or sacral regions.
Table 1. Patient and procedural characteristics

\begin{tabular}{|l|c|l|c|l||}
\hline Gender & Age & Procedure & Region & $\begin{array}{l}\text { Intervention } \\
\text { Technique(s) }\end{array}$ \\
\hline Male & 88 & Kypho & T \& L & ESI \\
\hline Male & 83 & Vert & L & ESI \\
\hline Female & 85 & Kypho & T & ESI \& IC \\
\hline Female & 91 & Vert & T \& L & ESI \\
\hline Female & 69 & Kypho & L & SI \& TPI \\
\hline Female & 76 & Kypho & T & ESI \\
\hline Male & 77 & Kypho & L & ESI \\
\hline Female & 89 & Sacroplasty & S & ESI, SI \& lumbar face \\
& & Vert \& Kypho & L & Lumbar facett \\
\hline Male & 68 & Kypho & T & ESI \\
\hline Female & 85 & Kypho & T & ESI \& TPI \\
\hline Female & 93 & Kypho \& Vert & T & ESI \& ICN \\
\hline Female & 84 & Kypho & L & ESI \\
& & Kypho & L & ESI \\
\hline Female & 78 & Kypho & L & TPI \\
\hline Male & 83 & Kypho & T & ESI \\
\hline Male & 82 & Vert & T & ESI \\
\hline Female & 81 & Kypho & L & TPI \\
\hline Female & 84 & Kypho & T & ESI \\
\hline Female & 72 & Vert \& Kypho & L & ESI \\
\hline Male & 88 & $\begin{array}{l}\text { Kypho } \\
\text { Kypho }\end{array}$ & T L & ICN \& TPI \\
\hline
\end{tabular}

\begin{tabular}{|l|c|l|c|l||}
\hline Gender & Age & Procedure & Region & $\begin{array}{l}\text { Intervention } \\
\text { Technique(s) }\end{array}$ \\
\hline Female & 85 & Kypho & T & SI \\
\hline Male & 89 & Sacroplasty & S & ESI \\
\hline Female & 85 & Kypho & L & ESI \\
\hline Female & 81 & Kypho & $\begin{array}{r}\text { T } \\
\text { S }\end{array}$ & ICN \\
\hline Female & 81 & Kypho & L & SI \\
Fypho & SI \\
\hline Female & 61 & Kypho & L & SI \\
\hline Female & 71 & Kypho \& Vert & T & ESI \\
\hline Female & 73 & Kypho & T & ESI \\
\hline Female & 85 & Kypho & T & ICN \\
\hline Female & 83 & Sacroplasty & S & ESI \\
\hline Male & 79 & Vert & L & ESI \\
\hline Male & 89 & Kypho & L & ESI \\
\hline Male & 88 & Kypho & T & ICN \\
\hline Male & 82 & Kypho & L \& T & ESI \\
\hline Male & 83 & Kypho & L \& T & ESI \\
\hline
\end{tabular}

$\mathrm{T}=$ thoracic; $\mathrm{L}=$ lumbar; $\mathrm{S}=$ sacral; $\mathrm{ESI}=$ =pidural steroid injection; ICN=intercostal nerve block; SI=sacroiliac joint injection; TPI=trigger point injection 
Chronic spinal pain is a multifactorial disorder with many possible etiologies. In the lumbar spine, Kuslich et al (10) identified intervertebral discs, facet joints, ligaments, fascia, muscles, and nerve root dura as tissues capable of transmitting pain in the low back. Facet joint pain, discogenic pain, and sacroiliac joint pain have been proven to be common causes of pain with proven diagnostic techniques (1). Thus, in patients presenting with pain in the spine with evidence of vertebral fractures, other structures may be involved including intervertebral discs, facet joints, ligaments, fascia, muscles, and nerve roots. This study showed most of the pain to be originating from discs, nerves, muscles, and sacroiliac joints based on the treatment provided and the response. The common belief that in fractures of the vertebral body, facet joints will be the sources of residual pain was not proven in this retrospective evaluation.

Even though many publications have reported significant short- and long-term pain relief following vertebral and sacral augmentation procedures, there are no reports in the literature of interventional techniques applied to manage residual pain after vertebral augmentation. In this retrospective review, $23.61 \%$ of the patients continued to suffer with residual pain.

In this practice, epidural steroid injections were performed most commonly, with 9 of 26 patients receiving thoracic epidural injections. Six patients were treated with intercostal nerve blocks.

This evaluation is limited by its retrospective nature and a small number of patients. Further, no systematic evaluation was performed to identify the pain generators responsible for the residual pain to appropriately arrive at proper diagnosis. Precision diagnostic techniques utilizing controlled diagnostic blocks must be applied. In spite of all the limitations, it is well known that observational studies are the mainstay of the literature for initial reports and for complications in general. Considering that there have not been any studies in this era, this retrospective evaluation should provide appropriate information for future controlled prospective studies. In addition, due to the retrospective nature of the study we have not utilized outcome measures with functional psychological status. Further, in a prospective setting, the role of conservative treatment in persistent residual pain may also be evaluated.

\section{Conclusion}

A small proportion of patients undergoing percutaneous cement augmentation for vertebral compression fractures or sacral insufficiency fractures reported residual pain and required interventional procedures including epidural injections, intercostal nerve blocks, facet joint injections, sacroiliac joint injections, and trigger point injections. Of all the injections, epidural injections were most commonly performed in the total population, whereas intercostal nerve blocks were the most common procedures in the thoracic spine.

\section{Acknowledgments}

The author wishes tothank Laxmaiah Manchikanti, $M D$, for his assistance in reviewing and providing helpful comments in the preparation of this manuscript. The author also wished to thank Tonie Hatton and Diane Neihoff, transcriptionists, for assistance in preparation of this manuscript.

\section{References}

1. Boswell MV, Trescot AM, Datta S, Schultz DM, Hansen HC, Abdi S, Sehgal N, Shah RV, Singh V, Benyamin RM, Patel VB, Buenaventura RM, Colson JD, Cordner HJ, Epter RS, Jasper JF, Dunbar EE, Atluri SL, Bowman RC, Deer TR, Hansen HC, Staats PS, Smith HS, Burton AW, Kloth DS, Giordano J, Manchikanti L. Interventional techniques: Evidencebased practice guidelines in the management of chronic spinal pain. Pain Physician 2007; 10:7-112.

2. Taylor RS, Taylor RJ, Fritzell P. Balloon kyphoplasty and vertebroplasty for vertebral compression fractures: A comparative systematic review of efficacy and safety. Spine 2006; 31:2747-2755.
3. Hulme PA, Krebs J, Ferguson SJ, Ber- 7 lemann U. Vertebroplasty and kyphoplasty: A systematic review of 69 clinical studies. Spine 2006; 31:1983-2001.

4. Old J, Calvert M. Vertebral compression fractures in the elderly. Am Fam Physician 2004; 69:111-1116.

5. Hall SE, Criddle RA, Comito TL, Prince 9 RL. A case-control study of quality of life and functional impairment in women with long-standing vertebral osteoporotic fractures. Osteoporos Int 1999; 9:508.

6. Report on Osteoporosis in the European Commission. European Commission, DG Employment, Industrial Relations and Social Affairs, 1998.
Silverman SL. The clinical consequences of vertebral compression fracture. Bone. 1992; 13:S27-S31.

8. Burton AW, Rhines LD, Mendel E. Vertebroplasty and kyphoplasty: A comprehensive review. Neurosurg Focus 2005; 18:E1.

Kim TK, Kim KH, Kim CH, Shin SW, Kwon JY, Kim HK, Baik SW. Percutaneous vertebroplasty and facet joint block. J Korean Med Sci 2005; 20:1023-1028.

10. Kuslich SD, Ulstrom CL, Michael CJ. The tissue origin of low back pain and sciatica: A report of pain response to tissue stimulation during operation on the lumbar spine using local anesthesia. Orthop Clin North Am 1991; 22:181-187. 